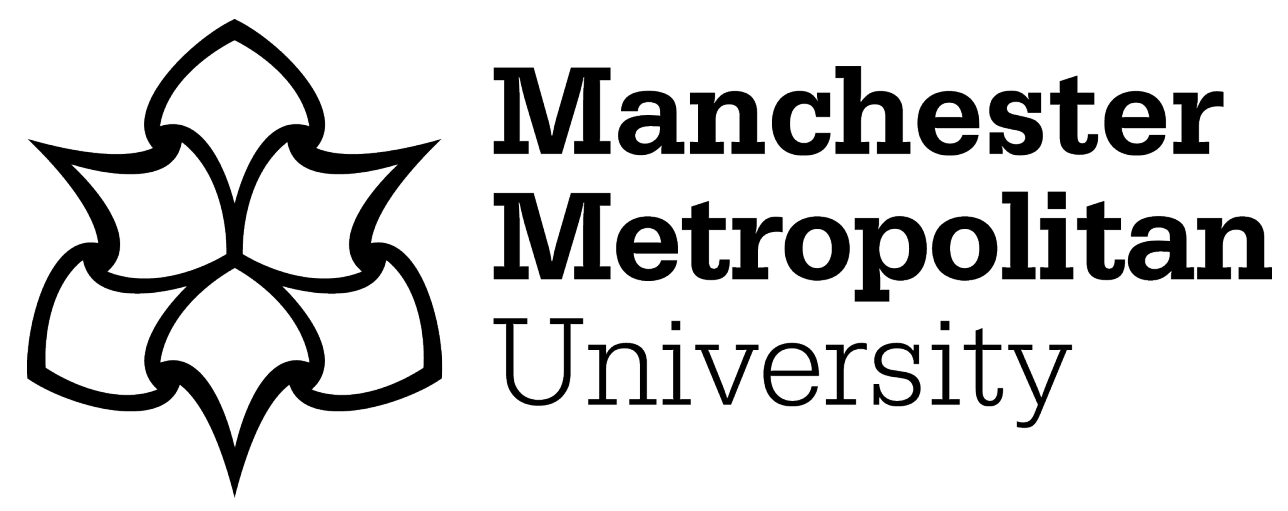

Gulson, KN and Sellar, S ORCID logoORCID: https://orcid.org/0000-00022840-5021 (2018) Emerging data infrastructures and the new topologies of education policy. Environment and Planning D: Society and Space, 37 (2). pp. 350-366. ISSN 0263-7758

Downloaded from: https://e-space.mmu.ac.uk/623391/

Version: Accepted Version

Publisher: SAGE Publications

DOI: https://doi.org/10.1177/0263775818813144

Please cite the published version 


\title{
Emerging data infrastructures and the new topologies of education policy
}

\begin{abstract}
This paper examines how datafication is creating new topologies of education policy. Specifically, we analyse how the creation of data infrastructures that enable the generation, communication and representation of digital data are changing relations of power, including both centralised and dispersed forms, and space in education. The paper uses conceptual resources from cultural topology and infrastructure studies to provide a framework for analysing spatial relations between educational data, discourses, policies and practices, in new governance configurations. The paper outlines a case study of an emergent data infrastructure in Australian schooling, the National Schools Interoperability Program, to provide empirical evidence of the movement, connection and enactment of digital data across policy spaces. Key aspects of this case include the ways that data infrastructure is: i) enabling new private and public connections across policy topologies; ii) creating a new role for technical standards in education policy; and, iii) changing the topological spaces of education governance.
\end{abstract}




\section{Emerging data infrastructures and the new topologies of education policy}

This paper examines how datafication is creating new topologies of education policy. We aim to provide new theorisations and empirical evidence to understand how the creation of data infrastructures, which enable the generation, communication and representation of digital data, is contributing to the emergence of digital educational governance (Williamson, 2016) and changing relations of power and space in education.

We aim to engage in conversation with two key literatures. The first is the literature on critical geographies of education (Pini, Gulson, Kraftl \& Duffy-Jones, 2017; Nguyen, Cohen \& Huff, 2017), or more specifically the geographies of education policy (e.g., Basu, 2007). This work has primarily focused on the ways in which education policy performs a spatial ordering of organisations, such as schools, and especially the connections between policy, schools and urban change (Butler, Hamnett \& Ramsden, 2013; Gulson, 2011). Relational notions of space and place, including mobility (e.g., Cohen, 2017), have informed these inquiries. In this paper, we build on this work by utilising topological theorisations of space (Martin and Secor, 2014) that have recently been introduced into studies of education policy and data in education (e.g., Lewis \& Hardy, 2017; Thompson \& Cook, 2014).

The second literature is that which makes new and novel connections between public policy, infrastructure and governance (Sage et al., 2015; Prince, 2016), with a focus on data. Lawn (2013a: 8) argues that 'the creation and flow of data has become a powerful governing tool in education,' in a similar manner to the focus on calculation, metrics and benchmarking in urban policy (e.g., McCann, 2008). In education producing the right second order objectives (numbers) has become as important as first order objectives (pedagogy, curriculum, assessment) in new performative accountability regimes. While the use of data and statistics has been central to the governing of the modern nation state, and, as such, a 
longstanding feature of formal schooling, new emphasis is now given in globalised education policy to performance and administrative data that are produced and used in, and by, schools, governments, education businesses and international organisations (Lingard and Sellar, 2013). Hence, there is an emerging body of literature in education and geography that attempts to identify and conceptualise processes of data-driven decision making in schools and systems, and the implications for policy, politics and practices of governance (Fenwick et al., 2014; Finn, 2016; Selwyn, 2015; Williamson, 2015).

Increasing data production, interpretation and use forms part of the shift from government to new modes of network governance through 'self-organizing, interorganizational networks' (Rhodes, 1997: 15, original emphasis). This concept of governance reflects the shift away from hierarchical and centralised modes of government towards distributed, multi-actor networks in which governments perform a co-ordinating function. For example, Lawn (2013b) argues that devolution in schooling is producing 'systemless systems' in which data flows sustain relations across systems that are fragmenting. Many education systems now derive much of their cohesiveness as a system from a common 'set of data processes and coded behaviours' (240). Underpinning these datadriven systems is an assumption that data can be generated, mobilised and used across diverse spaces and places, as part of:

the production of new regimes of knowledge and associated modes of 'social control' within organizational paradigms. The emergent 'algorithmic architectures' are computational systems of governance that hold a variable relation between the mathematical execution of code and an 'external' environment defined through arrangements of data. (Rossiter, 2017: 4) 
New modes of education governance are underpinned by data infrastructures that join up computer-based data management systems and integrate statistical information from various sources (Anagnastopolous et al, 2014; Sellar, 2015; Hartong, 2018; Rupert, 2012; Williamson, 2017). These infrastructures are an important element in contemporary schooling, which increasingly operates in network modalities that connect a range of organisations and actors, from schools and local school boards to state and provincial education ministries, commercial providers of education products and services, national education departments and international organisations, such as the Organisation for Economic Co-operation and Development (OECD). These networks become 'new governmental constellations that are constituted by (digital) data flows ... that create various new linkages and spaces between the global and the local' (Hartong, 2018, p. 138).

Our engagement with the concept of infrastructure draws on the field of infrastructure studies (Edwards, Jackson, Bowker \& Wilson 2009) that emerged with the study of computing and information systems during the 1990s. Infrastructure studies is part of the broader field of science and technology studies that has examined modern sociotechnical practices of classification, standardisation and networking (e.g. Hanseth, Monteiro \& Hatling, 1996; Star \& Ruhleder, 1996; Star 1999). More recent focus on infrastructure in the social sciences and humanities has extended the focus from the social dimension of infrastructure to theorise the cultural and logistical substrata of contemporary life (e.g. Berlant, 2015; Larkin, 2013; Rossiter 2017). We outline in more detail below our specific conceptualisation of infrastructure, which draws from Easterling's (2014) notion of infrastructure space. For now, we define data infrastructure as information systems that are designed to make data usable for organisational purposes, from local area networks to distributed cloud-based computing (Edwards et al. 2009; Kitchin 2014). Infrastructure is not simply an underlying arrangement of technical objects and systems, but also includes a variety of more intangible elements and 
practices: habits of thought, subjectivities, social practices and so on. Infrastructure is thus constituted from, and constitutes, social relations, cultures, desires and beliefs, and in relation to governance, it is constituted by, and constitutes, various modes of both centralised and dispersed power.

We are interested in exploring the connection between data infrastructures and the changing empirical topologies of network governance. Ball and Junemann (2012), among others (Au and Ferrare, 2015; Olmedo, 2013), have documented the emergence of this mode of governance in education, arguing that policy networks have created 'new sites and “opportunities" for influence on the policy process. The topology of policy is changed' (Ball and Junemann, 2012: 78). This change has not only been produced by the participation of new actors in education policy contexts, but also by reconfiguration of the spaces of political action in education. As Williamson (2016: 5) suggests, this involves the rise of 'digital education governance', in which '[t] he monitoring and management of educational systems, institutions and individuals is taking place through digital systems that are normally considered part of the backdrop to conventional policy instruments and techniques of government'.

We aim to contribute new conceptual resources for analysing these emergent modes of governance in education and to provide empirical evidence of the movement, connection and enactment of digital data across policy spaces. First, we outline how data infrastructure, as a particular form of cultural topology, provides a framework for analysing spatial relations between educational data, discourses, policies and practices in new governance configurations. Second, we apply this framework to a case study of an emergent data infrastructure in Australian schooling: the National Schools Interoperability Program (NSIP). We examine how this data infrastructure is: (i) enabling new private and public connections across policy topologies; (ii) creating a new role for technical standards in education policy; 
and, (iii) changing the topological spaces of education governance. We conclude by arguing, following Easterling (2014), that the creation of data infrastructures is producing new forms of 'extra-statecraft': systems that enable de-facto forms of governance in excess of formal government structures and regulatory processes.

\section{Cultural topology and infrastructure: A framework for policy analysis}

This section outlines different ways in which topological thinking has been taken up in cultural and social theory, including in human geography, and draws connections between conceptions of topology and infrastructure. In geography, interest in topology has been a response to possible limitations of topographical approaches to spatial thinking, such as structure-agency dichotomies. The topological approach fits within the broad remit of relational approaches to geography (Anderson and Harrison, 2010; Massey, 2005; Murdoch, 2006) in which 'space, place and politics ... [are] encountered, performed, and fluid' (Jones, 2009: 489).

Our approach involves the use of topology and associated concepts 'mildly, but responsibly loosened from the contexts in which they traditionally have been defined' (Martin and Secor, 2014: 434). Topology is primarily a mathematical concept that emerged in response to "the perceived rigidities of geometric shapes and surfaces that take their cue from the clear-cut coordinates of Euclidean space' (Allen, 2011: 285). In education and geography, recent work on policy engages with mathematical or cultural topologies (e.g., Thompson and Cook, 2014), with a particular focus on analysing new forms of education policy governance emerging from the prevalence of data use across multiple scales (Lewis, Sellar and Lingard, 2016). Some work has looked to show how topology can supplement topographical approaches to understanding policy mobility by combining a focus on the materiality of, and 
interconnections between, places, and the spaces that emerge in the processes of measurement and calculation (Prince, 2016).

Topologies preserve key properties and relationships under deformation. Network topologies provide a clear example of such forms and are our primary focus. Consider, for example, a map of the London Underground that represents the tube network as a relationship between nodes. The location of the stations (nodes) on the map does not correspond directly with the location of the stations in the space of the city as represented on a topographical map. Moreover, the map could be organised entirely differently and, providing the links between nodes were not broken, it would not lose any functionality. As Easterling argues, in relation to infrastructure space, 'the length and breadth of connections matter[s] less than the way in which things are connected' (Easterling, 2014: 289).

Martin and Secor (2014: 428) have asked: 'what is the status of topology in geography?' 'Is topology useful because it helps us to explain what space is or how space works (in all times and places), or is it useful because it corresponds to the dominant trends of our current historical conjuncture?' We would answer both questions in the affirmative, concurring with Lury et al.'s (2012: 6) argument that 'culture is becoming topological' at the same time as we are seeing an increase in the 'use of topology as a way of analysing culture'. The take up of topology in social theory is thus a new trend in social analysis that corresponds to the emergence of new cultural spaces. As Lury et al. (2012: 6) argue, 'the becoming topological of culture does not simply correspond to how culture imagines topology... topology is now emergent in the practices of ordering, modelling, networking and mapping that co-constitute culture, technology and science'.

The move from government to governance, as noted above, has involved a shift from hierarchical tree topologies to network topologies, which create new possibilities for power to operate through territories that cut across established spatialities, where 'presence and 
proximity are no longer simply a question of physical distance' (Allen, 2011: 295). For example, with the global spread of computer-based data management systems, and other information and communication technologies, data infrastructures play an important and influential role in the contemporary reworking of 'steering at a distance' (Kickert, 1995). The concept of power topologies enables an understanding of how data infrastructures: (1) constitute new relations between bodies of various kinds (e.g. people, organisations); and, (2) create forces that both produce and operate across these network spaces. Indeed, we are interested in topological and infrastructural power relations that are 'not so much positioned in space or extended across it', but rather 'compose the spaces of which they are a part' (Allen, 2011: 284).

Topological approaches to social and cultural analysis, especially when taken up in policy analysis, help draw attention to how practices of measurement, comparison, rankings and ratings, work 'both to introduce new continuities into a discontinuous world by establishing equivalences or similitudes, and to make and mark discontinuities through repeated contrasts' (Lury et al., 2012: 4). This production of continuities and discontinuities establishes new power relations between actors and things, new spatialities and new possibilities for action. In the sections that follow, we explore these ideas in relation to an emerging data infrastructure in Australian schooling.

\section{Case study: The National Schools Interoperability Program}

Our case study draws from a large multi-national comparative research project examining data infrastructures, policy mobility and network governance in education, with fieldwork undertaken in Australia, Canada, Japan and the United States (Gulson et al., 2017). The focus of this case is not data per se, but rather the work that has enabled the movement and use of 
data in school systems. We think this is an important distinction to make with methodological innovations enabling social science to explore digital cultural practices (e.g., Rogers, 2013). There is an emerging body of work on the conceptual and methodological tools necessary to understand and investigate the relationships between the subjects of data in education (e.g. teachers and students) and the collection and flows of data (e.g., Lupton, 2018). This is an important area of work, but our aim is to provide a descriptive account of the development of public infrastructure, with particular emphasis on the accounts of technical actors involved in this work.

The fieldwork has involved over 70 face-to-face interviews with policy makers, educators, managers and technicians in schools, school boards, education departments and ministries and commercial organisations. We asked questions such as: What administrative and performance data are being created and collected in schools and systems? How and why are these data being used? Who are the audiences for these data? What are the infrastructures that enable the production, dissemination and use of these data? And what new relations are generated as a result of the increasing prominence of data infrastructures in schools and systems?

Part of the Australian fieldwork focused on the National Schools Interoperability Program (NSIP). NSIP is a joint initiative of Federal, State and Territory Ministers for Education in Australia that is implementing interoperability standards to ensure consistent data formats in schools nation-wide. Its status as a joint initiative is important in the context of Australian education, which comprises different sectors that have their own governance structures: state (public) schools, Catholic schools and independent schools. Additionally, schooling is constitutionally a State and Territory responsibility, however, all sectors are publicly funded - either partially or wholly - by both the Federal and State or Territory governments. Australia has recently introduced a national approach to curriculum and 
accountability and there is now a rationale for consistent approaches to data collection and management nationally. Enabling such consistency is the aim of NSIP.

We conducted six interviews with government and commercial actors involved in the work of NSIP across 2016 and 2017. We also conducted extensive document analysis of relevant websites, technical reports and promotional materials relating to NSIP, interoperability standards in education and similar initiatives in other contexts (e.g., inBloom in the United States) (Sellar, 2017; Sellar and Gulson, 2018). The following sections outline findings from the NSIP case.

\section{Interoperability standards and the infrastructure of policy topologies}

Policy networks are increasingly being underpinned by infrastructural spaces produced as, and through, distributed modes of socio-technical power. Easterling's (2014) notion of infrastructure comprises more than the physical objects, such as the roads and rails or cables and pipes, that characterise infrastructure in a vernacular sense. Rather, infrastructure includes 'shared standards and ideas that control everything from technical objects to management styles' (Easterling, 2014: 11). Contemporary standards-setting forums include private international non-government, organisations such as the International Organization for Standardization, which is effectively 'an extra-state parliament' that brings together private companies and national representatives to support the creation of seemingly 'innocuous technical specifications' that nonetheless 'dictate the world's critical dimensions' (Easterling, 2014: 18). As Rossiter (2017: 98) argues, '[s]tandards are everywhere. Their capacity to interlock with one another and adapt to change over time and circumstance are key to their power as non-state agents of governance in culture, society, and the economy'.

One example of the growth and spread of data standards is the Schools Interoperability Framework (SIF), which specifies common data formats and enables data exchange between 
school and student information systems and other software. The key aim of NSIP is to implement SIF to make interoperable the information systems used by government and nongovernment schools and school systems across Australia, which have historically operated their own information systems with idiosyncratic data formats (Sellar, 2017). Bill Gates first announced SIF at the US School Administrator's Annual Conference in 1999 (SIF Association, 2012). Gates described the need for school districts to develop 'digital nervous systems' built on data standards in order to take 'a big step forward for both the educational software industry and schools' (Microsoft Corp., 1999). Following this announcement, Microsoft led the development of SIF with the support of 18 other software companies and the Software and Information Industry Association (SIIA), along with the US Department of Education. A global SIF organisation, the Access 4 Learning (A4L) community, was launched in 2015 to bring together SIF associations that have emerged in North America, the UK and Australia over the previous 15 years. The A4L community is a "non-profit collaboration composed of schools, districts, local authorities, states, US and International Ministries of Education, software vendors and consultants who collectively address all aspects of learning information management and access to support learning' (www.a4l.org). A4L argues that SIF now constitutes 'the most comprehensive data model and mature infrastructure interoperability framework in use globally in education' (A4L, 2015).

While SIF has been established for over 20 years, we argue that it now has a role underpinning and facilitating novel modes of governance by making data-driven publicprivate relations more efficient. An Organisational Lead for NSIP explained that:

... the standard that we mainly deal with, SIF, which has been around for twenty years, is a market-based standard developed collaboratively with schools and product providers over that period. ... I'm not sure that what we're doing here is creating a new source of 
ideas. The ideas are already out there, and they've been practiced, but not very efficiently, in the past. (Organisational Lead, NSIP)

Australian Ministers of Education agreed to adopt and develop an Australian specification of SIF in 2009, and NSIP was established in 2010 (http://www.nsip.edu.au). Chief Information Officers (CIOs) from each State and Territory education system, along with representatives from Catholic and Independent school sectors, direct NSIP through a steering group that consults a technical advisory group. A relatively small team undertake the day-to-day technical work. The hybrid organisational structure of NSIP was described to us by a Technical Lead:

NSIP is a kind of strange thing. It's not quite a ministerial company, but... we fall under the Australian government... . Our steering group is made up of all of the CIO's from the states and territories, and other reps as well, so the Australian government is there. I think as we go forward...we'll see more and more ... business representation in that group as well. (Technical Lead, NSIP)

NSIP is closely aligned with the Australian SIF Association (SIF AU), which currently has around 40 members, including governments and government bodies, Catholic and Independent school bodies, and commercial vendors. These members play a role in the development and management of the Australian specification of the standard:

We typically do some preliminary modelling, then you put it back to the folks and they see it. It goes through a whole working group process, which is part of the kind of the SIF structure, the standard structure here in Australia. Then if that's approved from a technical level, it goes to the policy level board, which is [Chief information Officer's] 
and some selected vendor members, and if that gets the okay it passes on, so it is governed all the way through. There's no opportunity for new pieces to just arise in the standard. (Organisational Lead, NSIP)

The structure and processes of NSIP are illustrative of the ways in which this infrastructure building project is bringing together public and private actors in standards-setting forums that are shaping the conditions for different modes of digital governance in Australian schooling. One governance concern for NSIP, especially among those who work with the management committee at the jurisdiction level, is to clarify and define the relationships between companies and the emerging data infrastructure. A further concern is that vendors do not drive the agenda and that demand for technical developments should come from schools: '[Changes to SIF are] nearly always there because schools have asked for them. It really starts with schools' (Organisational Lead, NSIP).

Standards can be both open and proprietary. SIF is an open standard co-developed with vendors and NSIP works to implement the standard to reduce costs for vendors and to provide benefits in relation to the procurement and supply of products and services between schools and vendors. NSIP provides an alternative to proprietary standards across the different education sectors in Australia:

We've had a lot of support from the vendor community, because, yes, lock in is one part of it, but proprietary integration is incredibly painful and expensive. Actually, it means ... [a vendor's] product is not economic, so if you get to that level playing field where you can all share, then you have to compete on features, and that's where they'd rather be, because there's not much in it in terms of competing over integration. It doesn't even help you sell it to the school. It's just a sink cost ... (Technical Lead, NSIP) 
Educational technology vendors have co-developed the SIF standard, and while this has obvious future benefits for these companies, the Chief Information Officer (CIO) of one of the larger Australian educational technology companies explained how the SIF standard has created new relationships not only between the state and companies, but companies themselves:

Anybody who's ever been involved in software knows that ... Any standardisation process never happens quickly. ... Having said that, it was a very valuable exercise in taking [SIF from] what was a conceptual data model from something that we could actually all work with and actually use as an agreed standard, ... And ...that was pretty unusual, to get a bunch of competitors together in the EdTech market to say, 'Let's actually work together for something that doesn't benefit us commercially directly, but does benefit us in terms of ... the ability to go out and consume our solution, because the long-term goal is, as a vendor, I could then go to anybody that supports SIF, and theoretically we could just start exchanging data and working together'. (CIO, Educational Technology Company)

As indicated here, providing schools with the ability to 'consume our solution' requires an open process that enables markets to emerge (Callon, 1998). Standards also regulate the ways in which schooling is perceived and performed, and infrastructure of this kind thus helps to constitute 'the rules governing the space of everyday life' (Easterling, 2014: 11). In the case of NSIP, these rules and spaces have evolved into the form of a national Learning Services Architecture. 


\section{The Learning Services Architecture: An emergent infrastructure}

Data infrastructure is a 'medium of information' that can be likened to an 'operating system' or 'spatial software', 'an updating platform unfolding in time to handle new circumstances' (Easterling, 2014: 14). This perspective complements recent work on data and governance (Williamson, 2016) by drawing attention to new relations of power and space that are made possible and conversely those that are made, if not impossible, then unlikely. Infrastructures work to create new power topologies in education through: physical manifestations of data in education spaces (e.g. data visualisations); the introduction of a new generation of information management systems and education software; rapidly increasing capacities for data analysis; and, bringing in new actors to provide the technical expertise required to develop and maintain the infrastructure.

Data generated across multiple scales and spaces by public and private agencies are becoming increasingly joined-up in education. NSIP is facilitating this 'joining up' through the creation of a Learning Services Architecture (LSA), which is one of the most fully developed data infrastructures in education globally. It has been enabled by what a Technical Lead of NSIP described as:

a kind of national architecture passion ... The nice thing about where we are in Australia is that it actually exists, so this is not something that we're putting forward as an aspiration to get to in five years' time; we can talk quite concretely about where everybody is and the state of different pieces, the jurisdictions, the market, the vendors ... What the Learning Services Architecture boils down to is that we have an agreed set of patterns across the country, which reflects a change ... the whole market forces inside education have shifted. So there was a time when jurisdictions would see themselves as being the providers of software to schools. You give to schools the systems that they're 
going to use, increasingly driven by ... kind of macroeconomic but also philosophical policy drivers. There's a move for autonomy in schools, in every sense. (Technical Lead, NSIP, our emphasis)

The national Learning Services Architecture (LSA) is a conceptualisation of NSIP's efforts to integrate information systems across schools, school systems and commercial vendors (Figure 1). Figure 1 represents the role of the SIF standard as information flows (in the middle of the diagram) and the ways that SIF enables interoperability (the common interfaces at the bottom). We are particularly interested in how the establishment of data hubs and information contracts (top left) are creating a new approach to managing data in Australian education.

[Insert Figure 1 here].

Similar to other countries, there have been substantial shifts in the governance of public schools in Australia with moves to local school autonomy in public education, and the use and management of data has become a key part of a hub (education departments) and spoke (schools) model. These networks are similar in the Catholic system and there are also groups of Independent schools that have quasi-system features. There has been a shift in the requirement for schools to manage data and, concomitantly, for systems to manage schools as semi-autonomous organisations. The LSA creates an architecture that connects these sectors the hubs and spokes - via a data infrastructure that supports market provision of products and services, with the intention that 'schools use the local systems that best meet their local needs' (Figure 1). Australian State and Territory education departments have agreed to purchase SIF-compliant student information systems when replacing current systems and this 
has meant a change in procurement practices from the central provision of software, such as from education departments, to more direct relations between schools and vendors, and systems and schools, via the SIF standard. As a Technical Lead outlines:

So the role [of NSIP] is one of saying... 'we can have a much more profound and useful impact as information providers if we focus, actually, on the good governance and management of information, and we leave the actual delivery of the functionality to the market and the things that schools choose', but it isn't a free-for-all. (Technical Lead, NSIP)

Through its use of SIF, NSIP has created the conditions for new relationships between governments, schools and commercial providers, based on the management and movement of data, conditions that have also created a new national topological space of governance that overlaps with, but is also distinct from, that which came before. NSIP introduces new continuities and creates new contrasts (Lury et al., 2012) with Australia's federal system of education, while creating a new topological policy space in which the management of data and governance converge around new kinds of agreements such as privacy contracts, a 'National Identity Management Framework' and what are called 'data hubs, brokers and adapters' in every state and sector in Australia. The NSIP website explains that:

[i]n the next 3-5 years the CIOs of all education jurisdictions see a significant shift in their role in the market. This shift will be for education jurisdictions to act as information hubs, exposing student, staff and school data to trusted third party developers, with the expectation that the market will provide products of value to schools that make use of that information. (http://www.nsip.edu.au/hits-hub-integration-testing-service) 
One of the key instruments in the LSA, and the underpinning 'trusted developer' relationship with 'hubs', are 'nationally agreed information contracts'. These contracts address data privacy issues. NSIP does not store any data from the jurisdictions (or hubs), but it does facilitate the movement of data. The issue of privacy is of concern for NSIP because, globally, data infrastructures are emergent sites of a politics focused on who has access to data and under what conditions. For example, in the US the rollout of inBloom, an ambitious centralised platform for data sharing, backed by the Bill and Melinda Gates Foundation, collapsed, partly related to privacy concerns and 'the combination of the public's low tolerance for risk and uncertainty and the inBloom initiative's failure to communicate the benefits of its platform and achieve buy-in from key stakeholders' (Bulger et al., 2017: 3). In the case of NSIP, the lessons of inBloom have been explicitly referenced, and NSIP's response has been to create an 'information contract': 'In terms of [the] learning service architecture, everything is expressed as an information contract' (Technical Lead, NSIP).

A data infrastructure using information contracts creates a different form of policy context that 'deforms' the existing jurisdictional systems, and relationships between schools, systems and companies via the SIF standard and the NSIP infrastructure.

So, we're seeing a change, really, where ...we have this idea of what we refer to as the 'data hubs', and it's really about saying that going forwards there's an information contract between schools and the Centre, rather than a software or an operational contract. (Technical Lead, NSIP).

Information contracts are illustrative of contemporary modes of governance and the spaces across which they operate. Ozga (2009: 150) argues that ' $[\mathrm{t}]$ he shift to governance is ... 
heavily dependent on knowledge and information, which play a pivotal role both in the pervasiveness of governance and in allowing the development of its dispersed, distributed and disaggregated form'. Information contracts, furthermore, represent how network governance brings together private and public actors into collaboration around public policy problems.

\section{New forms of private-public relationships in data infrastructures}

Market reforms in school systems, along with restructuring of state bureaucratic systems, first through new public management and then through network governance, have witnessed myriad forms of endogenous privatisation in schooling (Ball and Youdell, 2008). Governing through data is one development that is involving new private actors in education policy processes. Schools and school systems produce swathes of data, from administrative data relating to staff, students and school finances to testing and other forms of assessment data. However, a dramatic growth in performance data generated from assessments of various kinds is helping to rework relations between education agencies and education technology companies globally. In the coming years, many assessments will be moved online, further increasing the quantity and type of data that are generated (Williamson, 2015), and increasing the role of private education technology providers. Our interest here is less in the new forms of privatisation in assessment, but rather in the quite mundane, but nonetheless significant, aspects of school and system administration. The development and implementation of datadriven educational infrastructures is creating opportunities for commercial providers of databased products and services to participate in novel ways in education governance. The growth of of data infrastructure is, therefore, widening the set of policy actors who play a role in education.

From its early stages, NSIP has involved partnerships between government and education technology companies. The latter range in size and level of participation in NSIP, 
with many smaller companies that were established by ex-education administrators or parents (Sellar and Gulson, 2018). The main product categories offered by the vendors involved with NSIP are information management systems, including student information systems and other school administration software. In addition to the companies that have been part of the development of SIF AU, education technology companies can access the NSIP platform via a type of infrastructure broker service provided by NSIP that connects companies to emerging areas of data use.

Part of what we do ... wherever we identify these potential kind of structural, technical gaps, we provide a whole bunch of tooling that we put out there to market for people to use... [A]nd that's why, if we identify those kind of technical gaps, we try and put tools out there to market; so NSIP doesn't sell anything, as it were, but we can kind of see those emerging patterns and sort of go, 'In the future, you're going to need to join these things together. Here's some tools for you to take and use, and do those things'. (Technical Lead, NSIP, our emphasis)

As the Technical Lead indicates, NSIP does not sell a product, but it is shaping the future possibilities of what is done with the data in Australian schooling by enabling new possibilities for joining up data sets - the infrastructure will function as 'an updating platform unfolding in time to handle new circumstances' (Easterling, 2014: 14).

Furthermore, while not a commercial vendor, NSIP is facilitating interoperability that allows for data mobility across the system, and NSIP offers companies development frameworks, training and a testing service, called HITS, that enables access to dummy data for product development. Vendors can test whether their particular software packages are interoperable before tendering for a project, or to develop commercial off-the-shelf products 
or services that can be marketed to a broader customer base. Prior to NSIP, the latter needed to be done on a contract-by-contract basis. The Technical Lead states:

... HITS, in effect, is a virtual jurisdiction, so it populates with well-designed dummy data. So as a user we give accounts to any vendor who wants to participate, so again, it's a free service. Other than asking us for a log-in, [as a vendor] you don't have to pay anything, and what it does is, when you go in you can say, 'Well, I'd like to pretend I'm working with a jurisdiction of 500 schools, I want fifty classes in each, this kind of mixture of teachers' ... so you can set all these parameters, and in the back we generate all of the data that will then mimic the jurisdiction. Then you're free to just interact with it. (Technical Lead, NSIP)

While tools of this kind create new market opportunities, identifiable personal data is not being exposed to vendors. Rather, NSIP is circumventing the need to discover data systems and structures at the beginning of each contract or project, thus reworking the relationships that constitute policy heterarchies in education. Ball notes that in heterarchies:

... different kinds of power relations may exist between the same elements at the same time. Various different kinds of such relationships and asymmetries are currently in play in policy heterarchies - e.g. partnerships, contracts, inspection, competition, performance management and regulation, sponsorship, consortia, matched funding, consultation, etc. Actors and organisations in a heterarchy may play different roles, use different capabilities and exercise different forms of power, at the same time (Ball, 2009: 690). 
NSIP does not hold any of the data and this remains the responsibility of the parties in the information contracts. Rather, NSIP is enabling new relationships to be created between private and public actors as the state builds public infrastructure that acts as a quasi-incubator of the education technology market, minus the start-up funds. This infrastructure is a response to, but also further facilitates and intensifies, local school management.

Additionally, the governance relationships of NSIP are formed around data hubs that replicate the existing territories of educational governance (state authority over education), and bring multiple new actors into a topological infrastructure space (cross-sector, national education technology markets), thereby reforming jurisdictional (geographical) spaces and creating new connections between different educational sectors and actors. The enabling of new forms of data management by NSIP is thus helping to reconfigure education governance in Australia.

\section{Conclusion: Power topologies and extra-statecraft}

This paper has aimed to provide new theorisations and empirical evidence to show how emerging data infrastructures are creating new topologies of education policy. By focusing on data, policy and infrastructure as a topological space, we have highlighted that the integration of data and the creation of new data infrastructures, in addition to the infusion of business principles into school governance networks (Au and Ferrare, 2015), is contributing to intensified interactivity between people, networks and computational capacities that are central to the emergence of new modes of educational governance. We highlighted how concepts of infrastructure and topology open up possibilities for identifying how centralised and dispersed power operates through different territories that cut across established spatialities. 
The case of the NSIP Learning Services Architecture can be understood as newly created policy topology that has deformed and reformed an existing set of federal jurisdictions and state level responsibilities in education, and collapsed and reconfigured what have been separately governed sectors (independent, Catholic, public). The creation of a new federal governance structure becomes an infrastructure space or operating system that, through the use of data, can shape how education unfolds. In relation to network governance, policy topologies can help to map the complex terrain of governance distributed hierarchically and heterarchically, or more simply spatially (and less in a binary form of xaxis / y-axis). Topological concepts enable us to examine how infrastructures are reworking education governance, including by providing us with 'a way of thinking about relationality, space, and movement beyond metrics, mapping, and calculation' (Martin and Secor, 2014: 420). In the example of NSIP, the combination of standards, new forms of policy as information contracts, and the blurring of the private and public in the management of education data has created a deformation of previous governance structures and relationships. Emergent infrastructures bring in new subjects of education that expand the site of education from those in schools, such as teachers and students, to a broader set that includes corporate and technical actors. The account provided here focuses largely on the latter and thus participates in a broader refocusing of attention in audit societies away from first order practices (the practices of teachers and students) to second order objectives (measurements, targets and, in this case, the infrastructures that enable both) (Power 1997). The challenge for critical scholarship in geographies of education is to expand the analytical focus into new and complex technical practices without losing sight of the educational practices that data infrastructures are intended to support.

We want to conclude by reflecting on the role of 'extra-statecraft' as a useful way of thinking about this reworked governance. Easterling's notion of 'extra-statecraft' identifies 
the ways in which '[f]ar removed from familiar legislative processes, dynamic systems of space, information, and power generate de-facto forms of polity faster than even quasiofficial forms of governance can legislate them' (Easterling, 2014: 15). The concept of data infrastructure helps us to theorise how forms of educational governance are changing as digital governance and new relations of power create new spaces of extrastatecraft that intertwine with those of conventional statecraft.

The new topologies of policy require us to recognise two things: the simultaneity of different types of spatial and dispersed power relations (e.g., the co-existence of multiple networks); and the multiplicity of spaces, such as governance and data management, or of statecraft and extrastatecraft, that are no longer always separate, but are 'at certain times and places breaking in on each other' (Shields, 2013: 102). Schools and education bureaucracies are not being replaced by infrastructures like NSIP, but emerging data infrastructures do require that we recognise the possibility of schools and systems as multiple spaces in which existing relations are transformed by and within data infrastructures. And if we recognise this multiplicity of spaces, and of space itself, the contribution of power topologies as a conceptual tool both indexes empirical developments, for example those in educational governance identified as 'digital education governance' (Williamson, 2016), and frames new objects of analysis. For example, one challenge for future research is to follow flows of data, such as those that arise from the combination of achievement data (e.g., standardised testing data), demographic data and biometric/facial recognition data from classrooms as bioinformatics enters into education (e.g., de Freitas, 2017). Combining and analysing these different types of data is made possible by the introduction of machine learning (e.g., Gulson \& Webb, 2017). Indeed, the study of data infrastructure will very soon demand, if it does not already, close engagement with the development and use of Artificial Intelligence in education policy and practice. A focus on data-driven infrastructural power topologies and 
the algorithms that drive them can help us to identify new relations between the abstraction of data, the materiality of information systems and the visceral terrain of political life, with implications for how we might study emergent modes of power in educational policy and governance.

\section{Acknowledgements/ Funding here}

This paper is based on the research project Data infrastructures, mobility and network governance in education, funded by the Australian Research Council Discovery Project scheme (DP RG151529). The Chief Investigators are Bob Lingard, Kalervo N. Gulson, Keita Takayama and Sam Sellar. The Partner Investigators are Chris Lubienski and P. Taylor Webb. Thanks to the members of the team for comments on earlier versions of the paper.

\section{References}

A4L (2015) Introducing the Access 4 Learning Community - The SIF Association Matures to Address Not Only Data Management but Data Usage for Learning. Retrieved from https://www.sifassociation.org/NewsRoom/Press\%20Releases/Introducing\%20the $\% 2$ 0Access\%204\%20Learning\%20Community.pdf

Anagnastopolous D, Rutledge SA and Jacobsen R. (Eds.) (2013) The infrastructure of accountability: data use and the transformation of American education, Harvard Education Press: Cambridge, MA.

Allen J (2011) Topological twists: Power's shifting geographies. Dialogues in Human Geography 1: 283-298.

Anderson B and Harrison P. (2010) The promise of non-representational theories. In: B. Anderson B and Harrison P (eds) Taking-place: Non-representational theories and geography, Farnham: Ashgate, 1- 36. 
$\mathrm{Au} \mathrm{W}$ and Ferrare JJ. (2015) Introduction: Neoliberalism, social networks, and the new governance of education. In: Au W and Ferrare JJ (eds) Mapping corporate education reform: Power and policy networks in the neoliberal state. New York: Routledge, 122.

Ball SJ. (2009) Beyond networks? A brief response to 'which networks matter in education governance?'. Political Studies 57: 688-691.

Ball SJ and Junemann C. (2012) Networks, new governance and education, Bristol: The Policy Press.

Ball SJ and Youdell D. (2008) Hidden privatisation in public education: Education International Brussels.

Basu R. (2007) Negotiating acts of citizenship in an era of neoliberal reform: The game of school closures. International Journal of Urban and Regional Research 31: 109-127.

Berlant L. (2016) The commons: Infrastructures for troubling times. Environment and Planning D: Society and Space 34: 393-419.

Bulger M, McCormick P and Pitcan M. (2017) The legacy of inBloom, New York: Data \& Society Research.

Butler T, Hamnett C and Ramsden MJ. (2013) Gentrification, Education and Exclusionary Displacement in East London. International Journal of Urban and Regional Research 37: $556-575$.

Cohen D. (2017). Market mobilities/immobilities: mutation, path-dependency, and the spread of charter school policies in the United States. Critical Studies in Education 58: 168186.

Easterling K. (2014) Extrastatecraft: the power of infrastructure space, New York: Verso Books. 
Edwards PN, Bowker GC, Jackson SJ and Williams R. (2009) Introduction: an agenda for infrastructure studies. Journal of the Association for Information Systems 10: 6.

Fenwick T, Mangez E and Ozga J. (2014) Governing knowledge: Comparison, knowledgebased technologies and expertise in the regulation of education. In: Fenwick T, Mangez E and Ozga J (eds) Governing knowledge: Comparison, knowledge-based technologies and expertise in the regulation of education. London \& New York: Routledge.

Gulson KN. (2011) Education policy, space and the city: markets and the (in)visibility of race, New York: Routledge.

Gulson, KN, Lewis S, Lingard B, Lubienski C, Takayama K and Webb PT (2017) Policy mobilities and methodology: A proposition for inventive methods in education policy studies. Critical Studies in Education 58: 224-241.

Hanseth O, Monteiro E and Hatling M. (1996) Developing information infrastructure: The tension between standardization and flexibility. Science, Technology, \& Human Values 21: 407-426.

Jones, M. (2009) Phase space: Geography, relational thinking, and beyond. Progress in Human Geography 33: 487-506.

Kickert W. (1995) Steering at a distance: A new paradigm of public governance in Dutch higher education. Governance 8: 135-157.

Kitchin R. (2014) The data revolution: Big data, open data, data infrastructures and their consequences, SAGE: Los Angeles and London.

Larkin, B. (2013). The politics and poetics of infrastructure. Annual Review of Anthropology 42: 327-343. 
Lawn M. (2013a) Introduction: The rise of data in education In: Lawn M (ed) The rise of data in education systems: Collection, visualisation and use. Oxford: Symposium, 710.

Lawn M. (2013b) A systemless system: Designing the disarticulation of English state education. European Educational Research Journal 12: 231-241.

Lewis S and Hardy I. (2017) Tracking the topological: The effects of standardised data upon teachers' practice. British Journal of Educational Studies 65: 219-238.

Lewis S, Sellar, S and Lingard, B. (2016). PISA for Schools: Topological Rationality and New Spaces of the OECD's Global Educational Governance. Comparative Education Review 60: 27 -57.

Lingard B and Sellar S (2013) Globalization, edu-business and network governance: the policy sociology of Stephen J. Ball and rethinking education policy analysis. London Review of Education 11: 265-280.

Lupton D. (2018) How do data come to matter? Living and becoming with personal data. Big Data \& Society 5: doi:10.1177/2053951718786314.

Lury C, Parisi L and Terranova T. (2012) Introduction: The becoming topological of culture. Theory, Culture \& Society 29: 3-35.

Martin L and Secor AJ. (2014) Towards a post-mathematical topology. Progress in Human Geography 38: 420-438.

Massey D. (2005) For space, London: Sage Publications.

McCann EJ. (2008) Expertise, truth, and urban policy mobilities: Global circuits of knowledge in the development of Vancouver, Canada's 'four pillar'drug strategy. Environment and Planning A 40: 885-904.

Microsoft Corp. (1999). Schools Interoperability Framework Initiative Releases First Working Specification Following Successful School Pilots. Retrieved from 
https://news.microsoft.com/1999/11/10/schools-interoperability-framework-initiativereleases-first-working-specification-following-successful-schoolpilots/\#sm.0000yj2my01c0dswwc41t8rob1yxg

Murdoch J. (2006) Post-structuralist geography: A guide to relational space, London: SAGE Publications.

Nguyen N, Cohen D and Huff A. (2017) Catching the bus: A call for critical geographies of education. Geography Compass 11: e12323.

Olmedo A. (2013) From England with love... ARK, heterarchies and global 'philanthropic governance'. Journal of Education Policy 29: 575-597.

Ozga J. (2009) Governing education through data in England: From regulation to selfevaluation. Journal of Education Policy 24: 149-162.

Pini B, Gulson KN, Kraftl P and Duffy-Jones R. (2017) Critical geographies of education: an introduction. Geographical Research 55: 13-17.

Power M. (1997) The audit society: Rituals of verification, Oxford University Press: Oxford.

Prince R. (2016) The spaces in between: Mobile policy and the topographies and topologies of the technocracy. Environment and Planning D: Society and Space 34: 420-437.

Rhodes RAW. (1997) Understanding governance policy networks, governance, reflexivity and accountability, Buckingham: Open University Press.

Rogers R. (2013) Digital methods, Cambridge, MA: MIT press.

Rossiter N. (2017) Software, infrastructure, labor: A media theory of logistical nightmares, New York and London: Routledge.

Sage D, Fussey P and Dainty A. (2015) Securing and scaling resilient futures: Neoliberalization, infrastructure, and topologies of power. Environment and Planning D: Society and Space 33: 494-511. 
Sellar S. (2015) Data infrastructure: A review of expanding accountability systems and largescale assessments in education. Discourse: Studies in the Cultural Politics of Education 36: 765-777.

Sellar S. (2017). Making network markets in education: the development of data infrastructure in Australian schooling. Globalisation, Societies and Education 15: $341-351$

Sellar S and Gulson KN (2018) Dispositions and situations of governance: The example of data infrastructure in Australian schooling. In: Wilkins A and Olmedo A (eds) Education governance and social theory: Interdisciplinary approaches to research London: Bloomsbury.

Selwyn N. (2015) Data entry: Towards the critical study of digital data and education. Learning, Media and Technology 40: 64-82.

Shields R. (2013) Spatial questions: Cultural topologies and social spatialisations, London: SAGE Publications.

SIF Association (2012). The SIF Association celebrates 15 years! Retrieved from https://www.sifassociation.org/NewsRoom/Press\%20Releases/SIF\%20Association\%2 0Celebrates $\% 2015 \% 20$ Years.pdf

Star, S.L. (1999). The ethnography of infrastructure. American Behavioural Scientist 43: $377-391$.

Star, S., \& Ruhleder, K. (1996). Steps toward an ecology of infrastructure: design and access for large information spaces. Information Systems Research 7: 111-134.

Thompson G and Cook I. (2014) Becoming-topologies of education: deformations, networks and the database effect. Discourse: Studies in the Cultural Politics of Education: 117. 
Williamson B. (2015) Digital education governance: Data visualization, predictive analytics, and 'real-time' policy instruments. Journal of Education Policy: 1-19.

Williamson B. (2016) Digital education governance: An introduction. European Educational Research Journal 15: 3-13.

Williamson, B. (2017). Big data in education: The digital future of learning, policy and practice. London: SAGE Publishers. 
Figure 1 - Learning Services Architecture

\section{Better Data for Better Outcomes}

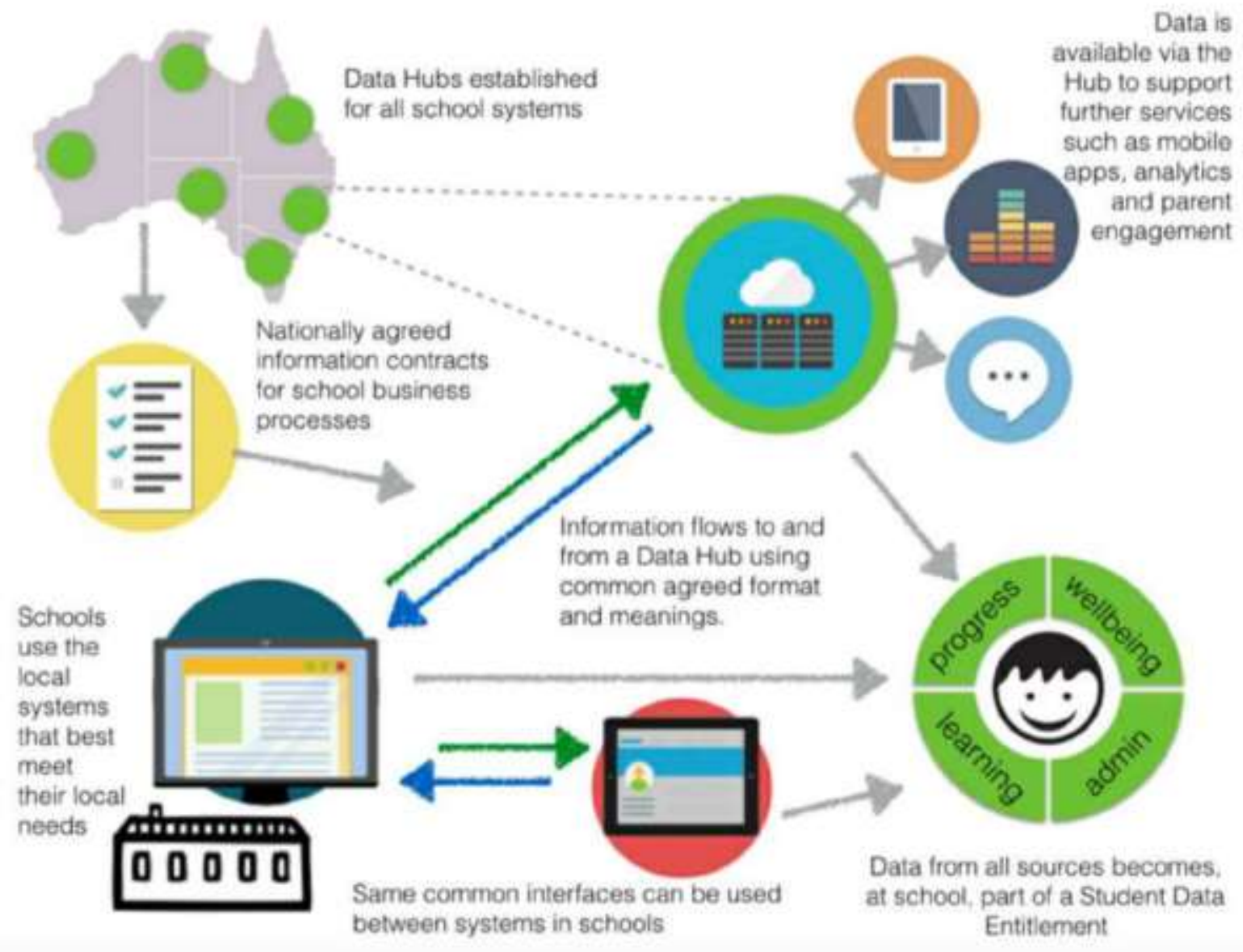

